\title{
Vasculitis séptica por Listeria monocytogenes
}

\author{
Cristián Vera-Kellet, Constanza Del Puerto, Felipe Ruiz, Sergio González y Jorge Manríquez
}

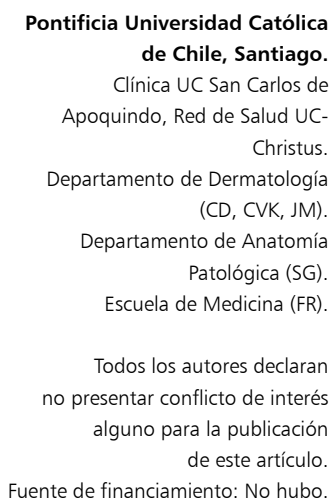

Todos los autores declaran no presentar conflicto de interés

alguno para la publicación de este artículo.

Fuente de financiamiento: No hubo.

Recibido: 22 de abril de 2014 Aceptado: 15 de septiembre de

Correspondencia a: Cristián Vera-Kellet cvera@med.puc.c

\section{Introducción}

L a vasculitis cutánea es una patología poco frecuente, con una incidencia descrita entre 15,4 y 29,7 casos por millón de habitantes por año ${ }^{1}$. Se presenta con leve predominio en mujeres y es más frecuente en adultos que en niños ${ }^{2}$. Se estima que 15 a $20 \%$ de todas las vasculitis cutáneas son desencadenadas o asociadas a infecciones ${ }^{3}$, $40 \%$ son idiopáticas, $20 \%$ son asociadas a reacción adversa a medicamentos, $12 \%$ asociadas a enfermedades del tejido conectivo y menos de $5 \%$ asociadas a neoplasias ${ }^{2}$. La mayoría de las vasculitis asociadas a infección se manifiestan como una vasculitis leucocitoclástica cutánea, sin compromiso sistémico y de curso autolimitado. En este caso, la infección, más frecuentemente respiratoria alta, actúa como un gatillante que lleva a la generación de complejos inmunes ${ }^{1}$. Sin embargo, en algunos pacientes que cursan con una sepsis, los microorganismos pueden diseminarse a la piel por vía hematógena y desencadenar una vasculitis séptica cutánea.

La vasculitis séptica (VS) es una vasculopatía que se presenta casi exclusivamente en el contexto de una bacteriemia. Corresponde a una de las cuatro alteraciones cutáneas que se pueden presentar en un paciente séptico, siendo las otras tres, la coagulación intravascular diseminada, la embolia séptica y la vasculitis leucocitoclástica por complejos inmunes. Debido a que la sepsis en sí misma es un cuadro grave, la VS se asocia a una alta letalidad ${ }^{4}$. Los microrganismos responsables son múltiples: bacterias, virus, hongos, protozoos y helmintos. Si bien, la VS se produce principalmente en el contexto de una sepsis por Neisseria meningitidis y Neisseria gonorrhoeae, también se han descrito casos de VS asociada a otros agentes ${ }^{1}$. Se presenta el primer caso de una vasculitis séptica secundario a Listeria monocytogenes en un paciente adulto mayor inmunocomprometido.

\section{Caso clínico}

Paciente de 71 años, de sexo masculino, con antecedentes de cardiopatía coronaria, flutter auricular, enfermedad mitro-aórtica, artritis reumatoide, síndrome de Sjögren, hipertensión arterial y hepatitis C. Presentaba una inmunosupresión de larga data y diabetes mellitus tipo 2 secundaria a terapia esteroidal. Estaba en tratamiento con prednisona 5-20 mg/día (dosis en reducción debido a una queratitis ulcerativa), leflunomida, amiodarona, acenocumarol, amlodipino, valsartán, atenolol y omeprazol.

Consultó por cuadro de una semana de evolución de astenia y aumento de volumen progresivo en la cara anterior de ambas piernas, asociado a un eritema sensible mal definido, fiebre $>38^{\circ} \mathrm{C}$ y taquicardia. Sin síntomas gastrointestinales, genitourinarios ni neurológicos. Fue hospitalizado con diagnóstico de una sepsis secundaria a celulitis, por lo que se inició tratamiento con cefazolina 1 g cada $8 \mathrm{~h}$ iv y clindamicina $600 \mathrm{mg}$ cada $8 \mathrm{~h}$ iv. Entre los exámenes de ingreso destacaban parámetros inflamatorios elevados con leucocitosis $22.300 \mathrm{cé} 1 / \mathrm{mm}^{3}(96 \% \mathrm{PMN}) \sin$ alteraciones al frotis y PCR 2,87 mg/dL (valor normal < $1,0 \mathrm{mg} / \mathrm{dL}$ ); con recuento de plaquetas normal, sedimento de orina sin alteraciones y función renal conservada. Se tomaron dos hemocultivos al ingreso de la hospitalización; uno de ellos resultó positivo para L. monocytogenes a las 22,5 h de incubación (identificadas por MS MALDI-TOF, crecimiento en agar sangre de colonias $\beta$-hemolíticas y test de CAMP positivo), por lo que se suspendió cefazolina y se agregó ampicilina $1 \mathrm{~g}$ cada $6 \mathrm{~h}$ iv, con lo que se logró remisión de la fiebre y mejoría de los parámetros inflamatorios. Se realizó un ecocardiograma que descartó una endocarditis infecciosa. Dentro de sus antecedentes epidemiológicos destacaba el consumo ocasional de alimentos mal cocidos.

Pese a la buena respuesta sistémica, durante la hospitalización se observó la aparición de lesiones purpúricas 


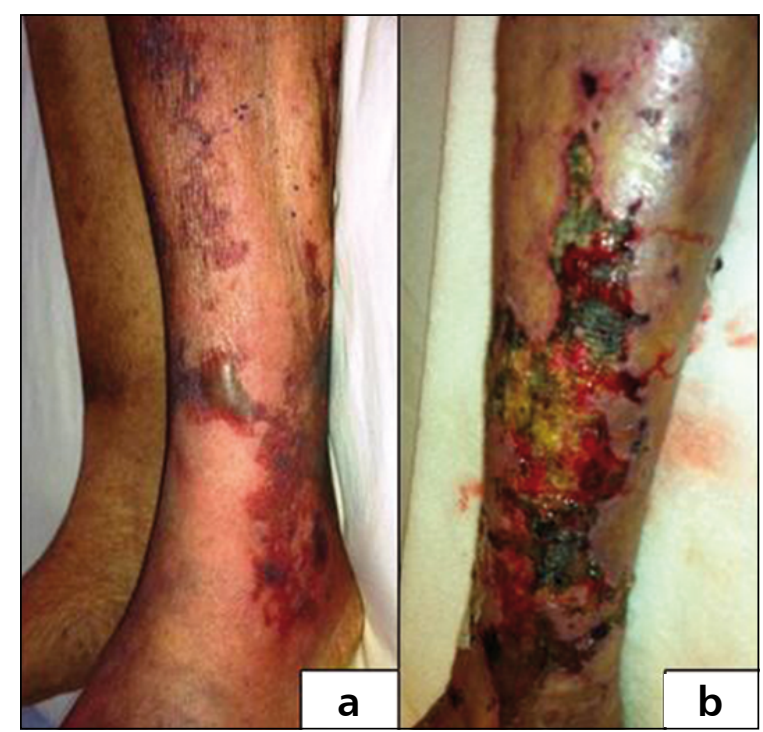

Figura 1a. Púrpura palpable con borde estrellado, centro más violáceo y flictenas al centro, en cara anterior y lateral de ambas piernas; (b) necrosis cutánea a las $48 \mathrm{~h}$.

retiformes, que coalescieron formando placas purpúricas de borde estrellado y livedo racemosa en la periferia, distribuidas en cara anterior de ambas piernas. Dichas placas evolucionaron rápidamente formando bulas $\mathrm{y}$ necrosis epidérmica (Figuras 1a y b). El paciente fue evaluado por Dermatología en donde se sospechó una vasculitis séptica versus una vasculitis secundaria a su artritis reumatoide, por lo que se decidió realizar una biopsia cutánea. El estudio histopatológico de las lesiones mostró un infiltrado dérmico intersticial polimorfo con linfocitos, polimorfonucleares y eosinófilos, asociado a un infiltrado inflamatorio de neutrófilos en los vasos dérmicos, con leucocitoclasia (Figura 2a). La tinción de Gram del tejido mostró cocobacilos grampositivos (Figura 2b), con tinción de PAS negativo. Los hallazgos fueron compatibles con una vasculitis séptica por Listeria spp. No se realizaron cultivos de tejido.

Se mantuvo la terapia antimicrobiana asociada y se inició terapia con corticoides sistémicos (prednisona 0,5 $\mathrm{mg} / \mathrm{kg} /$ día), además de manejo local de las lesiones con desbridamiento, curaciones diarias y aplicación tópica de mupirocina $2 \%$, clobetasol $0,05 \%$ y un cicatrizante tópico a base de chitosán (Biopiel $\AA$ ). Tras completar 7 días de clindamicina y 14 días de ampicilina iv el paciente evolucionó favorablemente con franca mejoría de las lesiones cutáneas. Se dio de alta con antibioterapia oral con amoxicilina $500 \mathrm{mg}$ cada $8 \mathrm{~h}$, por 14 días más. Finalmente, a cuatro meses del tratamiento, con curaciones dermatológicas bisemanales, se obtuvo resolución completa de lesiones cutáneas (Figura 3).
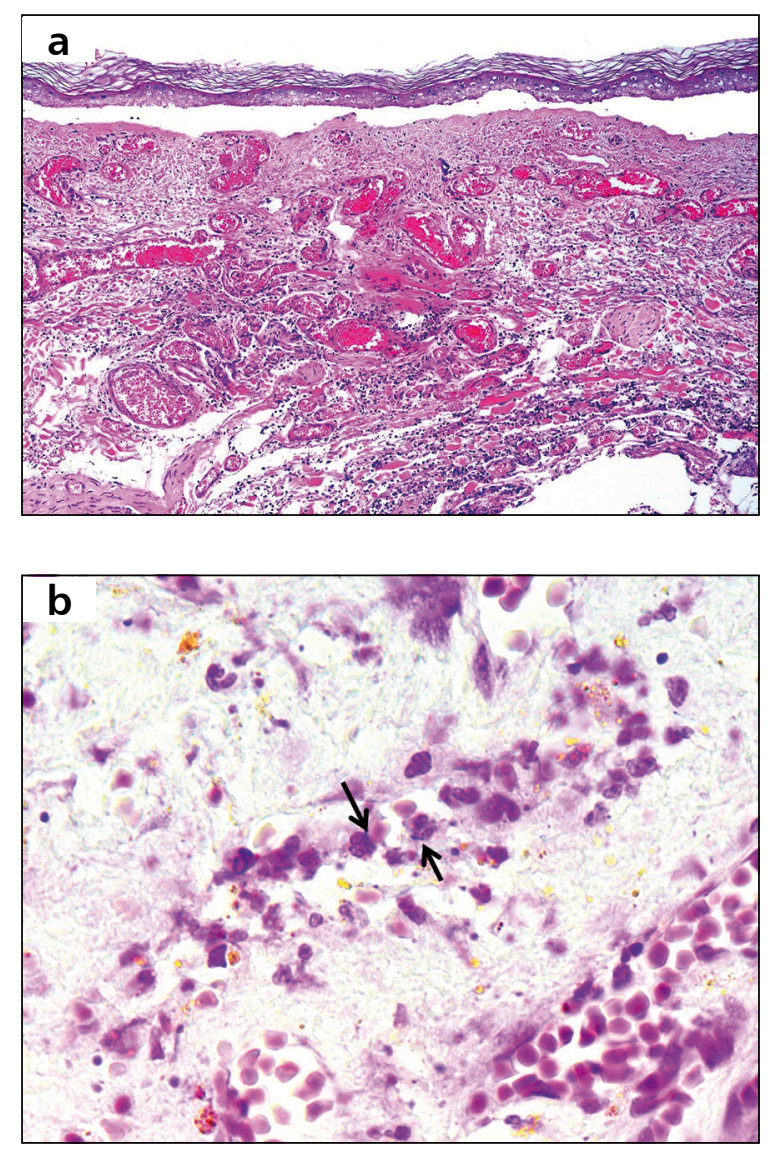

Figura 2a. Infiltrado inflamatorio en vasos de la dermis con predominio de neutrófilos, con leucocitoclasia; (b) Tinción de Gram, inmersión en aceite, $1.000 \mathrm{X}$. Se observan cocobacilos grampositivos agrupados (flechas).

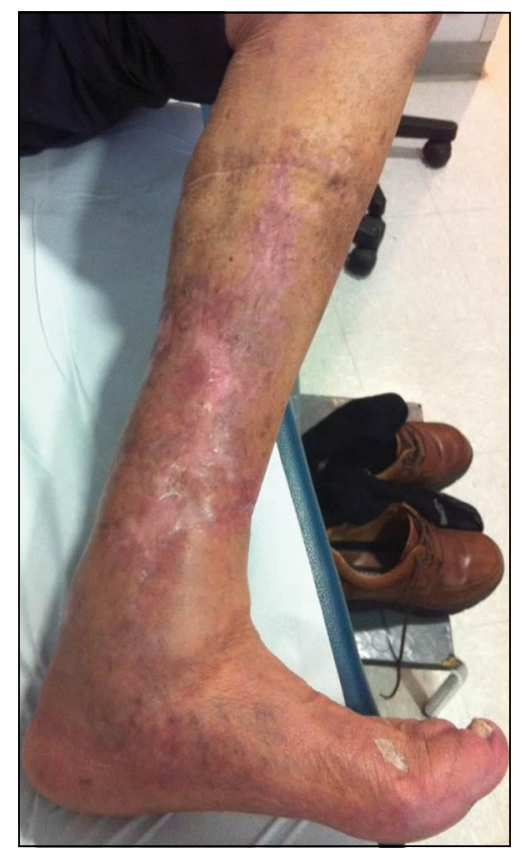

Figura 3. Lesiones cicatriciales en pierna derecha luego de 12 semanas de tratamiento. 


\section{Discusión}

La VS es un cuadro infrecuente, que suele presentarse en pacientes inmunocomprometidos. Clínicamente se presenta como un púrpura retiforme de tipo inflamatorio, con bulas, úlceras y necrosis. Histopatológicamente, se observa un infiltrado neutrofílico en los vasos pequeños y medianos de la dermis profunda e hipodermis, con leucocitoclasia ${ }^{1}$ asociado a la presencia de abundantes microorganismos en las células endoteliales, constituyendo una vasculitis necrosante con trombosis vascular ${ }^{4,5}$. Se diferencia de la vasculitis leucocitoclástica secundaria a infecciones porque la VS carece de depósitos de complejos inmunes y porque en la vasculitis leucocitoclástica no se observan microorganismos en los vasos.

Respecto al agente infeccioso causal, la VS se produce mayormente en contexto de una meningococcemia, seguido de gonococcemia. En la literatura médica se han descrito otros agentes asociados a este cuadro como Staphylococcus aureus, Streptococcus pyogenes, Streptococcus pneumoniae, Pseudomonas spp. y Rickettsias spp., entre otros ${ }^{1-5}$. Sin embargo, no existen casos reportados de VS por L. monocytogenes.

La listeriosis es una zoonosis que se transmite principalmente por vía digestiva por consumo de alimentos contaminados o contacto con animales. Es causada por la bacteria L. monocytogenes, un bacilo grampositivo corto, no esporulado, anaerobio facultativo ${ }^{6,7}$. En algunas ocasiones puede aparecer como cocáceas en diplo ${ }^{7}$. Puede aislarse en el suelo, agua y contenido fecal de muchos animales. Debido a que tiene la capacidad de resistir temperaturas de refrigeración, $\mathrm{pH}$ extremos y altas concentraciones de sal, es un contaminante común de alimentos de origen animal y vegetal, leche y lácteos no pasteurizados ${ }^{6}$. En cuanto a su epidemiología, es una enfermedad infrecuente, con una incidencia que oscila entre 0,1 y 11,3 casos por millón de habitantes ${ }^{8}$. En Chile, se reportan cerca de 50-100 casos al año. Según el Ministerio de Salud de Chile (MINSAL), en los años 2012 y 2013, se reportaron 79 y 83 casos, respectivamente ${ }^{9}$.

La ingesta de alimentos contaminados con Listeria spp, produce una colonización gastrointestinal por la bacteria sólo en $1-10 \%$ de $\operatorname{los} \operatorname{casos}^{6}$, causando la ma- nifestación clínica más frecuente de la listeriosis: una gastroenteritis aguda en pacientes sanos ${ }^{10}$. Sin embargo, en pacientes inmunocomprometidos, como es el caso de nuestro paciente, la infección produce formas invasoras asociadas a diseminación hematógena: sepsis, meningitis, infecciones perinatales (por transmisión vertical) ${ }^{10} \mathrm{y}$ menos frecuentemente, encefalitis y abscesos cerebrales ${ }^{6}$. Debido a la bacteriemia puede producirse una endocarditis secundaria y diseminación de émbolos sépticos a distancia (hígado, bazo, ojo, huesos) ${ }^{11}$. La población de riesgo para desarrollar formas de listeriosis invasora son los recién nacidos, mujeres embarazadas, pacientes inmunocomprometidos y ancianos. Sin embargo, también se han visto casos, menos frecuentemente, en adultos inmunocompetentes ${ }^{6}$.

En cuanto a las manifestaciones cutáneas de la listeriosis, éstas son más frecuentes en recién nacidos con formas diseminadas como la granulomatosis infanto-séptica y en personas que desarrollan labores ocupacionales ligadas al contacto con animales ${ }^{12}$. Se han descrito casos de celulitis y linfadenitis en agricultores y veterinarios por inoculación directa del bacilo ${ }^{11}$.

Hasta la fecha no se han comunicado en publicaciones en inglés o español, casos de vasculitis séptica secundaria a L. monocytogenes. Se presenta un caso sin precedentes en la literatura médica por su interesante forma de presentación, en que a pesar de la gravedad del cuadro de base, respondió favorablemente a la terapia.

\section{Resumen}

La vasculitis séptica es una inflamación de los vasos sanguíneos de pequeño y mediano calibre causada por la acción directa de agentes patógenos en el contexto de una sepsis. Es una condición infrecuente y se manifiesta clínicamente por lesiones cutáneas como púrpura, vesículopústulas e incluso úlceras. La mayoría de los casos de vasculitis séptica se asocian a una meningococcemia. No se han reportado casos en la literatura médica de vasculitis séptica secundaria a Listeria spp. Se presenta el caso de un hombre de 71 años, con cuadro de sepsis por Listeria monocytogenes y que presentó lesiones purpúricas con una biopsia compatible con una vasculitis séptica. 


\section{Referencias bibliográficas}

1.- Chen K R, Carlson J A. Clinical approach to cutaneous vasculitis. Am J Clin Dermatol 2008; 9: 71-92.

2.- Carlson J A, Cavaliere L F, Grant-Kels J M. Cutaneous vasculitis: diagnosis and management. Clin Dermatol 2006; 24 : 414-29.

3.- Pulido-Pérez A, Avilés-Izquierdo J A, Suárez-Fernández R. Vasculitis cutáneas. Actas Dermosifiliogr 2012; 103: 179-91.

4.- Delgado-Jiménez Y, Fraga J,
Fernández-Herrera J, García-Diez A. Vasculopatía séptica. Actas Dermosifiliogr 2007; 98 (Suppl 1): 22-8.

5.- Crowson A N, Mihm M C Jr, Magro C M. Cutaneous vasculitis: a review. J Cutan Pathol 2003; 30: 161-73.

6. Benadof D. Listeria monocytogenes. Rev Chilena Infectol 2008; 25: 350

7.- Posfay-Barbe K M, Wald E R. Listeriosis. Semin Fetal Neonatal Med 2009; 14: 228-33.

8.- Swaminathan B, Gerner-Smidt P. The epidemiology of human listeriosis. Microbes Infect 2007; 9: 1236-43.
9.- MINSAL. Informe de la situación de Listeria monocytogenes, Chile 2014 (SE 1 a 9 del 2014). http://epi.minsal.cl/epi/html/bolets/reportes/ Listeriosis/Listeria_SE092014.pdf (Acceso: 20 de julio de 2014).

10.- Allerberger F, Wagner M. Listeriosis: a resurgent foodborne infection. Clin Microbiol Infect 2010; 16: 16-23.

11.- Doganay M. Listeriosis: clinical presentation. FEMS Immunol Med Microbiol 2003; 35 173-5.

12.- Godshall C E, Suh G, Lorber B. Cutaneous listeriosis. J Clin Microbiol 2013; 51: 3591-6. 